\title{
pH Variability Exacerbates Effects of Ocean Acidification on a Caribbean Crustose Coralline Alga
}

\author{
Maggie D. Johnson ${ }^{1,2,3 *}$, Lucia M. Rodriguez Bravo', Shevonne E. O'Connor4, \\ Nicholas F. Varley 5 and Andrew H. Altieri1,6
}

${ }^{1}$ Smithsonian Tropical Research Institute, Panama City, Panama, ${ }^{2}$ Smithsonian Marine Station, Fort Pierce, FL, United States, ${ }^{3}$ Tennenbaum Marine Observatories Network, Smithsonian Institution, Edgewater, MD, United States, ${ }^{4}$ Mount Holyoke College, South Hadley, MA, United States, ${ }^{5}$ Department of the Geophysical Sciences, University of Chicago, Chicago, IL, United States, ${ }^{6}$ Department of Environmental Engineering Sciences, University of Florida, Gainesville, FL, United States

OPEN ACCESS

Edited by: Nick Kamenos, University of Glasgow,

United Kingdom

Reviewed by:

Heidi L. Burdett,

The Lyell Centre, United Kingdom

Sophie J. McCoy,

Florida State University, United States

*Correspondence: Maggie D. Johnson johnsonmd4@si.edu

Specialty section: This article was submitted to Marine Ecosystem Ecology, a section of the journal Frontiers in Marine Science

Received: 17 November 2018 Accepted: 08 March 2019

Published: 26 March 2019

Citation:

Johnson MD,

Rodriguez Bravo LM, O'Connor SE, Varley NF and Altieri AH (2019) pH

Variability Exacerbates Effects of Ocean Acidification on a Caribbean

Crustose Coralline Alga.

Front. Mar. Sci. 6:150.

doi: 10.3389/fmars.2019.00150
Crustose coralline algae (CCA) are among the most sensitive marine taxa to the $\mathrm{pH}$ changes predicted with ocean acidification (OA). However, many CCA exist in habitats where diel cycles in $\mathrm{pH}$ can surpass near-future OA projections. The prevailing theory that natural variability increases the tolerance of calcifiers to OA has not been widely tested with tropical CCA. Here, we assess the response of the reefbuilding species Lithophyllum congestum to stable and variable $\mathrm{pH}$ treatments, including an ambient control (amb/stable). The amb/variable treatment simulated an ambient diel cycle in $\mathrm{pH}$ (7.65-7.95), OA/stable simulated constant low pH reflecting worstcase year 2100 predictions (7.7), and OA/variable combined diel cycling with lower mean $\mathrm{pH}$ (7.45-7.75). We monitored the effects of $\mathrm{pH}$ on total calcification rate and photophysiology (maximum quantum yield) over 16 weeks. To assess the potential for acclimatization, we also quantified calcification rates during the first (0-8 weeks), and second (8-16 weeks) halves of the experiment. Calcification rates were lower in all $\mathrm{pH}$ treatments relative to ambient controls and photophysiology was unaffected. At the end of the 16-week experiment, total calcification rates were similarly low in the amb/variable and OA/stable treatment (27-29\%), whereas rates declined by double in the OA/variable treatment (60\%). When comparing the first and second halves of the experiment, there was no acclimatization in stable treatments as calcification rates remained unchanged in both the amb/stable and $\mathrm{OA} /$ stable treatments. In contrast, calcification rates deteriorated between periods in the variable treatments: from a $16-47 \%$ reduction in the amb/variable treatment to a $49-79 \%$ reduction in the OA/variable treatment, relative to controls. Our findings provide compelling evidence that $\mathrm{pH}$ variability can heighten CCA sensitivity to reductions in $\mathrm{pH}$. Moreover, the decline in calcification rate over time directly contrasts prevailing theory that variability inherently increases organismal tolerances to low $\mathrm{pH}$, and suggests that mechanisms of tolerance may become limited with increasing time of exposure. The significant role of diel pH cycling in CCA responses to OA indicates that organisms in habitats with diel variability could respond more severely to rapid changes in ocean $\mathrm{pH}$ associated with $\mathrm{OA}$ than predicted by experiments conducted under static conditions.

Keywords: calcification, diel variability, global change, Lithophyllum congestum, pH, photophysiology 


\section{INTRODUCTION}

Ocean acidification (OA) is a leading global threat to the persistence of coral reefs and other calcifier-dominated marine habitats (Hoegh-Guldberg et al., 2007). Calcification by foundational taxa is essential to healthy habitat structure and ecosystem function (Vargas-Angel et al., 2015; Edmunds et al., 2016; Smith et al., 2016), but decreasing ocean $\mathrm{pH}$, and the associated changes in seawater carbon chemistry, impair calcification of reef-building corals and algae (Kroeker et al., 2010). Crustose coralline algae (CCA) are important ecosystem engineers in a variety of nearshore marine habitats (McCoy and Kamenos, 2015), including coral reefs, where they help build the three-dimensional carbonate framework of the reef, and stabilize the reef matrix via calcification (Bosence, 1985; Adey, 1998). However, they also secrete the most soluble polymorph of $\mathrm{CaCO}_{3}$ (high-Mg calcite) and are highly vulnerable to changes in carbonate chemistry associated with OA (McCoy and Kamenos, 2015). Negative effects of OA that result in decreased calcification rates or increased dissolution of CCA jeopardize the reef habitat framework and affiliated species (Eyre et al., 2014; Comeau et al., 2016).

Near-future OA models are based on the open ocean (Duarte et al., 2013), where rates of change in environmental conditions are relatively gradual and invariable over time (Hofmann et al., 2011). Until recently, the majority of perturbation experiments have used this as a basis for simulating OA with constant low $\mathrm{pH}$ treatments. However, many benthic organisms, including tropical CCA, inhabit nearshore ecosystems where environmental conditions, including $\mathrm{pH}$, fluctuate over multiple temporal scales (Takeshita et al., 2018). In these habitats, biophysical coupling between metabolism (e.g., photosynthesis and respiration) and physical properties of the water column can cause $\mathrm{pH}$ to fluctuate on a diel cycle (Kleypas et al., 2011). Photosynthetic depletion of $\mathrm{CO}_{2}$ increases $\mathrm{pH}$ during the day, release of $\mathrm{CO}_{2}$ through respiration decreases $\mathrm{pH}$ at night, and the magnitude of this cycle can be shaped by water residence time and community biomass (Duarte et al., 2013). In ecosystems dominated by photosynthetic organisms (e.g., coral reefs and seagrass meadows), the range of diel changes in $\mathrm{pH}$ can exceed the difference between current conditions and end-of-century OA projections for the open ocean (Hofmann et al., 2011; Duarte et al., 2013). In situ $\mathrm{pH}$ manipulations, such as free ocean carbon enrichment (FOCE) experiments (Kline et al., 2012) and studies using natural gradients in $\mathrm{pH}$ (e.g., $\mathrm{CO}_{2}$ vents and tide pools), have shed light the potential for natural variability to influence organismal and community-scale responses to $\mathrm{pH}$ reductions (Kroeker et al., 2013; Noisette et al., 2013; Stark et al., 2019). These experiments demonstrate how $\mathrm{pH}$ variability can influence the structure and trajectory of calcifier-dominated ecosystems (Kroeker et al., 2013) and can mediate the response of calcifiers to changes in mean pH (Georgiou et al., 2015). Applying this approach to manipulative experiments, by incorporating localscale $\mathrm{pH}$ variability into $\mathrm{pH}$ treatments, is a necessary step toward improving the predictive power and ecological relevance of laboratory perturbation experiments to nearshore ecosystems (Rivest et al., 2017; Vargas et al., 2017).
Exposure to environmental variability can increase organismal tolerances to subsequent environmental stress (Boyd et al., 2016) by facilitating phenotypic plasticity (i.e., acclimatization) or genotypic variation (i.e., adaptation) (van Oppen et al., 2015). An example of this environmental variability-stress acclimatization theory includes corals exposed to thermal variability that bleach less when faced with subsequent exposure to temperature extremes (Mayfield et al., 2012). pH variability is likewise proposed to increase organismal tolerances to OA (Anthony et al., 2011; Duarte et al., 2013; Vargas et al., 2017). If pH variability leads to enhanced tolerance to acidified conditions, it would have important implications for the response of sensitive taxa, such as CCA, and the functioning of marine communities, to near-future OA. However, this hypothesis has not yet been widely tested with tropical calcified algae (except see Johnson et al., 2014a; Cornwall et al., 2018). Alternatively, organisms from high variability habitats that are already surviving at their upper physiological limits may be less resilient to further environmental stress. While our knowledge of environmental drivers of genetic and phenotypic adaptation is relatively advanced for tropical corals (Palumbi et al., 2014), we know little about whether there is similar potential for CCA to acclimatize or adapt to environmental stress. Quantifying how environmental variability shapes organismal responses to $\mathrm{OA}$ is essential for understanding the effects of OA in an ecologically relevant context, to elucidating the environmental factors that influence species and habitatspecific sensitivities to $\mathrm{OA}$, and to improving our ability to predict ecosystem trajectories in response to OA.

Results from a handful of studies demonstrate that tropical CCA have the potential to acclimatize to past and present exposure to $\mathrm{pH}$ stress following exposure to $\mathrm{pH}$ variability. For example, a temperate CCA from a high variability site was resistant to subsequent exposure to stable low $\mathrm{pH}$ (PadillaGamiño et al., 2016). Likewise, tropical corallines with a history of exposure to high $\mathrm{pH}$ variability calcified more under moderate $\mathrm{pH}$ variability (simulating ambient $\mathrm{pH}$ variability) than corallines with a history of exposure to low $\mathrm{pH}$ variability (Johnson et al., 2014a; Cornwall et al., 2018). These two studies found that prior exposure to $\mathrm{pH}$ variability did not increase calcification under stable OA conditions, thus support for the hypothesis that $\mathrm{pH}$ variability increases tolerance to OA is mixed, at best, for tropical CCA. Conversely, some temperate coralline algae from tide pools with a highly variable $\mathrm{pH}$ regime were not more tolerant to $\mathrm{OA}$ than those from a stable $\mathrm{pH}$ regime (Noisette et al., 2013). Moreover, CCA may be more sensitive to $\mathrm{pH}$ variability, in the context of rapid and acute $\mathrm{pH}$ reductions that simulate upwelling or carbon capture and release, than to chronic low pH exposure (Kamenos et al., 2013). Collectively, these studies demonstrate that some corallines possess the potential to acclimatize to environmental conditions, that $\mathrm{pH}$ variability influences CCA calcification, and that prior exposure to variability may facilitate acclimatization. They also indicate that variability does not inherently increase tolerances to mean reductions in $\mathrm{pH}$. The limited number of studies and conflicting results make it difficult to disentangle the role of exposure to $\mathrm{pH}$ variability in shaping CCA responses to OA. As a result, it is unclear if tropical CCA fit the environmental variability-stress 
acclimatization theory that $\mathrm{pH}$ variability increases tolerances to OA (Anthony et al., 2011).

Though we have a cursory understanding of potential effects of $\mathrm{pH}$ variability on coralline calcification, less is known about potential interactions of $\mathrm{OA}$ with diel $\mathrm{pH}$ cycling. Only one study, to date, has tested the combined effects of lower mean $\mathrm{pH}(\mathrm{OA})$ with simultaneous exposure to diel $\mathrm{pH}$ variability in tropical CCA (Cornwall et al., 2018). This study found that variability superimposed on $\mathrm{OA}$ had no negative effects on net calcification in the tropical coralline Hydrolithon reinboldii, despite the increased time spent at extreme low $\mathrm{pH}$. Corallines can demonstrate species-specific responses to OA (Johnson et al., 2014b; Comeau et al., 2018) that could be linked to physiological control over calcification (Cornwall et al., 2018). Though some CCA appear to control intracellular carbonate chemistry at the site of calcification (Cornwall et al., 2017), the degree of control may influence their calcification response to $\mathrm{OA}$ and may vary by species (Comeau et al., 2018; Cornwall et al., 2018). The potential interactions of OA, diel variability, and species-specific susceptibilities to changing $\mathrm{pH}$, among other confounding factors, are highly complex. More work is needed to understand the potential effects of OA on tropical CCA in habitats with diel $\mathrm{pH}$ cycling.

To address these gaps, we exposed a common reef-building CCA (Lithophyllum congestum) to a combination of stable and variable $\mathrm{pH}$ treatments. We tested the hypotheses that exposure to $\mathrm{pH}$ variability increases the tolerance of a tropical $\mathrm{CCA}$ to $\mathrm{OA}$ and that $\mathrm{OA}$ combined with $\mathrm{pH}$ variability synergistically decreases CCA calcification. We quantified the effects of stable and variable $\mathrm{pH}$ on coralline net calcification rates and photophysiology after 16 weeks of exposure to these treatments. Additionally, we quantified calcification rates in the first and second 8-weeks of this period to explore the potential for acclimatization to different $\mathrm{pH}$ regimes. This approach allowed us to partition calcification rates into a total net response (0-16 weeks), an initial response (0-8 weeks), and a potential acclimatization response (8-16 weeks). By incorporating diel $\mathrm{pH}$ variability into an OA framework, we increase the relevance of our results to nearshore, environmentally variable ecosystems, and provide insight into the potential compounding effects of diel $\mathrm{pH}$ cycling and $\mathrm{OA}$ on a reef-builder with critical importance to coral reef ecosystems.

\section{MATERIALS AND METHODS}

\section{Specimen Collection}

Lithophyllum congestum is a heavily calcified crustose coralline alga that produces stout, blunt branches (Figure 1), and is an abundant framework builder on shallow coral reefs throughout the Caribbean (Adey, 1978). Fragments of L. congestum were collected at $3 \mathrm{~m}$ in Bahía Almirante in the Bocas del Toro archipelago off the Caribbean coast of Panamá. Specimens were collected with diagonal cutters and returned to the Smithsonian Tropical Research Institute (STRI), where they were maintained under ambient light and flow-through seawater until the start of the experiment. Fragments were cleaned of epiphytes with tweezers and attached to plastic Vexar bases with underwater epoxy (Aquamend), oriented with branch tips facing up. Exposed non-living carbonate underneath and around the base of fragments was coated with epoxy to prevent dissolution in acidification treatments. Specimens were allowed to recover from collection for 4 days in ambient light $(282 \pm 6 \mu$ mol photon $\left.\mathrm{m}^{-2} \mathrm{~s}^{-1}\right)$ and flow-through seawater $\left(29.0 \pm 0.5^{\circ} \mathrm{C}\right)$. Fragments were monitored for epiphytic growth every 3 days for the duration of the experiment and, when necessary, cleaned with a soft-bristle brush and tweezers.

\section{Experimental Design}

Our experiment was conducted in the temperature controlled aquarium facilities at STRI's Bocas del Toro Research Station (BRS) in Panamá from June - September 2017. L. congestum fragments were exposed to one of the following $4 \mathrm{pH}$ treatments for the 16-week experiment: ambient/stable (amb/stable), ambient/variable (amb/variable), OA/stable, and OA/variable. The amb/stable treatment consisted of seawater pumped from a depth of $3 \mathrm{~m}$ near the STRI dock and passed through a $50 \mu \mathrm{m}$ filter in the BRS seawater line. The variable treatments simulated a 0.3 unit diel cycle in $\mathrm{pH}$, with highest $\mathrm{pH}$ during peak daylight hours, and lowest $\mathrm{pH}$ at the end of the night. This represents daily changes in $\mathrm{pH}$ due to photosynthesis during the day and respiration during the night (Rivest et al., 2017; Takeshita et al., 2018). In the amb/variable treatment, $\mathrm{pH}$ ranged from 7.65 to 7.95 over $24 \mathrm{~h}$, simulating a moderate diel cycle in $\mathrm{pH}$ that is characteristic on some shallow coral reefs (Hofmann et al., 2011; Price et al., 2012; Guadayol et al., 2014). Further, these conditions approximate the $\mathrm{pH}$ regime at the collection site, where daily mean $( \pm \mathrm{SE}) \mathrm{pH}$ is $7.98 \pm 0.006$, minimum is 7.88 , and maximum is 8.03 (Johnson, unpublished data). In the OA/stable treatment, $\mathrm{pH}$ was maintained at $\sim 7.70$, simulating conditions projected in representative concentration pathway (RCP) 8.5 for the year 2100 (Hartin et al., 2016). pH ranged from 7.45 to 7.75 in the $\mathrm{OA} /$ variable treatment, superimposing the 0.3 unit diel cycle in $\mathrm{pH}$ over a lower mean $\mathrm{pH}$ and simulating potential conditions in nearshore habitats if reductions in $\mathrm{pH}$ associated with $\mathrm{OA}$ are overlaid with natural diel $\mathrm{pH}$ cycles. At the start of the experiment $\mathrm{pH}$ was gradually decreased by 0.05 units per day until treatment levels were reached, in order to minimize shock of rapid environmental change.

Experimental replicates were $2.8 \mathrm{~L}$ plastic tanks containing 3 L. congestum fragments, with 6 replicate tanks per treatment. Each tank received a continuous supply of ambient or treatment seawater at $15.7 \mathrm{~mL} \mathrm{~min}^{-1}$. Ambient seawater was plumbed from the BRS seawater line into each amb/stable tank. The $\mathrm{pH}$ of treatment seawater was manipulated in one of three reservoir tanks and then pumped into respective treatment tanks. Water was circulated in each tank with a small aquarium pump $\left(300 \mathrm{~L} \mathrm{hr}^{-1}\right)$. Treatments were assigned randomly to tanks and tanks were shuffled haphazardly every $2-3$ days to reduce the potential for positional effects (due to lighting or other unforeseen positional factors).

Temperature was maintained by controlling the ambient air temperature of the experimental room, set to $28^{\circ} \mathrm{C}$. Lighting was provided by 8, 7-color LED lights (Hydra52, Aqualllumination). 


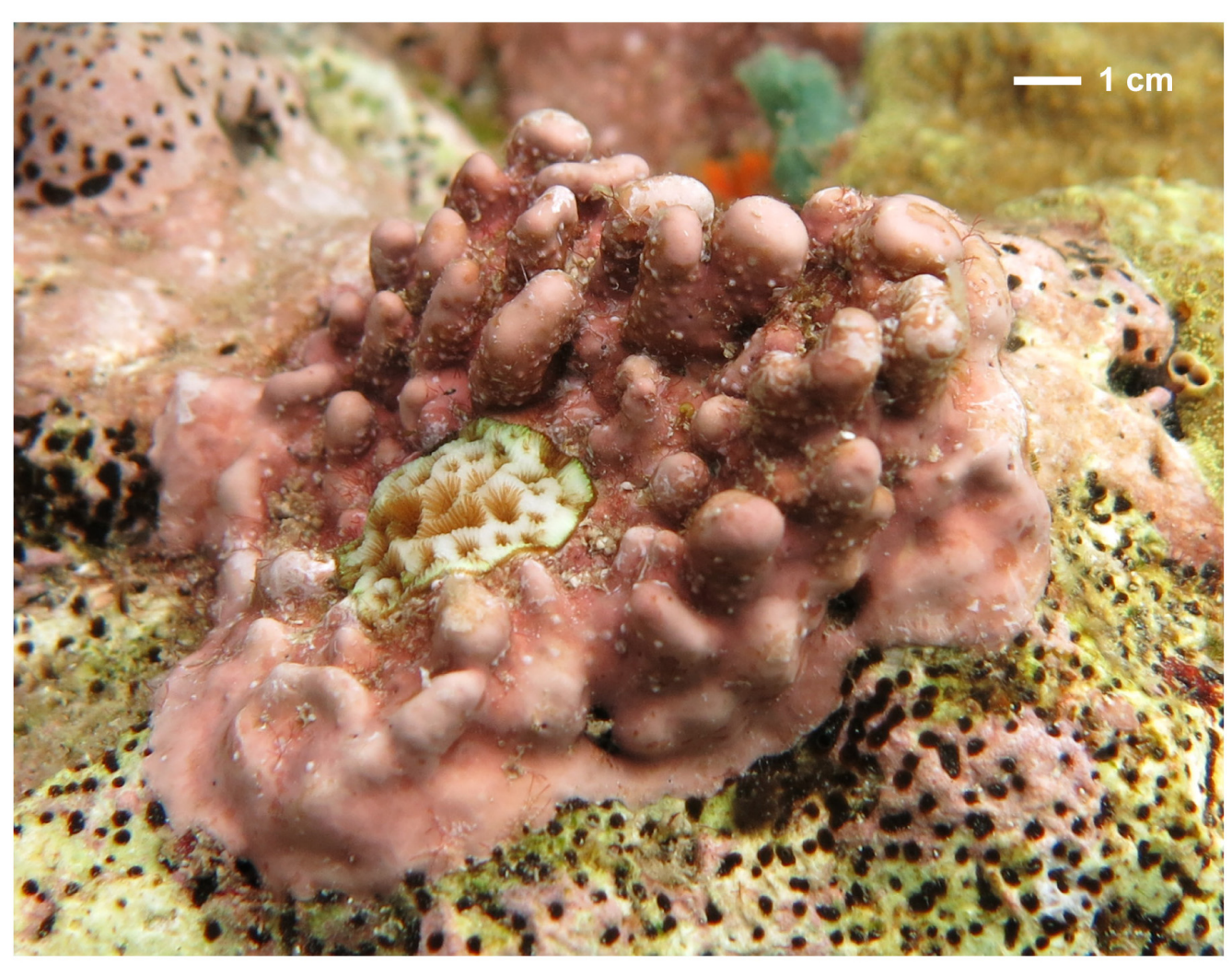

FIGURE 1 | Fragments of Lithophyllum congestum, a common reef-building crustose coralline alga on Caribbean coral reefs, were collected from a shallow coral reef in Bocas del Toro, Panamá and exposed to a combination of stable and variable pH treatments for 16-weeks. Though a coral is pictured alongside the CCA in situ, the fragments used in the experiment were comprised solely of $L$. congestum.

Lights were programmed to a 12:12 h photoperiod (0600-1800). Lights ramped up to maximum intensity over $4 \mathrm{~h}$ starting with sunrise and then ramped down starting $4 \mathrm{~h}$ before sunset. Peak midday irradiance mirrored photosynthetically active radiation (PAR) measured at the collection site and depth $(\sim 270 \mu \mathrm{mol}$ photon $\left.\mathrm{m}^{-2} \mathrm{~s}^{-1}\right)$. In situ irradiance was measured over one peak period on a sunny day with a LiCor meter (Li1400) and underwater cosine sensor (Li-193). During the experiment, light levels were measured between 1000 and 1400 (period of maximum intensity). Though light levels remained constant for the duration of the experiment, we measured light every 2-3 days when tanks were repositioned to avoid potential effects of tank position in relation to light sources.

\section{pH Manipulation and Carbonate Chemistry}

Treatment $\mathrm{pH}$ was manipulated in $75-\mathrm{L}$ reservoir tanks with pure $\mathrm{CO}_{2}$ and a $\mathrm{pH}$ feedback system. Each reservoir received a continuous supply of filtered, ambient seawater, with flow controlled by an automated float valve. $\mathrm{pH}$ was measured every minute in each reservoir with a lab-grade $\mathrm{pH}$ probe (Neptune), calibrated weekly with NBS buffers $(7,10)$ following factory protocol. Probes were connected to an Apex aquacontroller (Neptune) and solenoid valves, set to maintain $\mathrm{pH}$ within 0.1 of a target value. When $\mathrm{pH}$ increased above the set value, the solenoid valve opened and released pure $\mathrm{CO}_{2}$ until $\mathrm{pH}$ decreased to the set value. Diffusion of $\mathrm{CO}_{2}$ in each reservoir was facilitated by an aquarium pump (1600 $\left.\mathrm{L} \mathrm{hr}^{-1}\right)$ fitted with a venturi injector. Treatment water was pumped from each reservoir into respective treatment tanks with a separate aquarium pump. $\mathrm{pH}$ measurements from Neptune probes were cross-calibrated with daily, discrete $\mathrm{pH}$ measurements (described below). Settings were adjusted to maintain target $\mathrm{pH}$ conditions on the total scale $\left(\mathrm{pH}_{\mathrm{T}}\right)$. $\mathrm{pH}$ variability was established by programming the aquacontroller with incremental changes in the target values over a diel cycle. $\mathrm{pH}_{\mathrm{T}}$ in the variable treatments fluctuated by $\sim 0.3$ units over a diel cycle throughout the experiment, while $\mathrm{pH}_{\mathrm{T}}$ in the amb/stable and OA/stable treatments was held constant at $\sim 8.04$ and $\sim 7.70$, respectively (Figure 2 ).

Tank conditions were monitored daily between 0930 and 1030. $\mathrm{pH}$ was measured in each tank with a glass triode (Ross Ultra) connected to a $\mathrm{pH}$ meter (Orion Star) and calibrated with certified Tris buffer in synthetic seawater (Batch T30, A. Dickson). Temperature measurements were taken simultaneously with a traceable digital thermometer (Thomas Traceable Kangaroo). Salinity was measured every 2-3 days in reservoir tanks with a handheld YSI (YSI-63). Salinity of treatment tanks matched salinity of reservoir tanks due to high flow rates from the reservoir. 


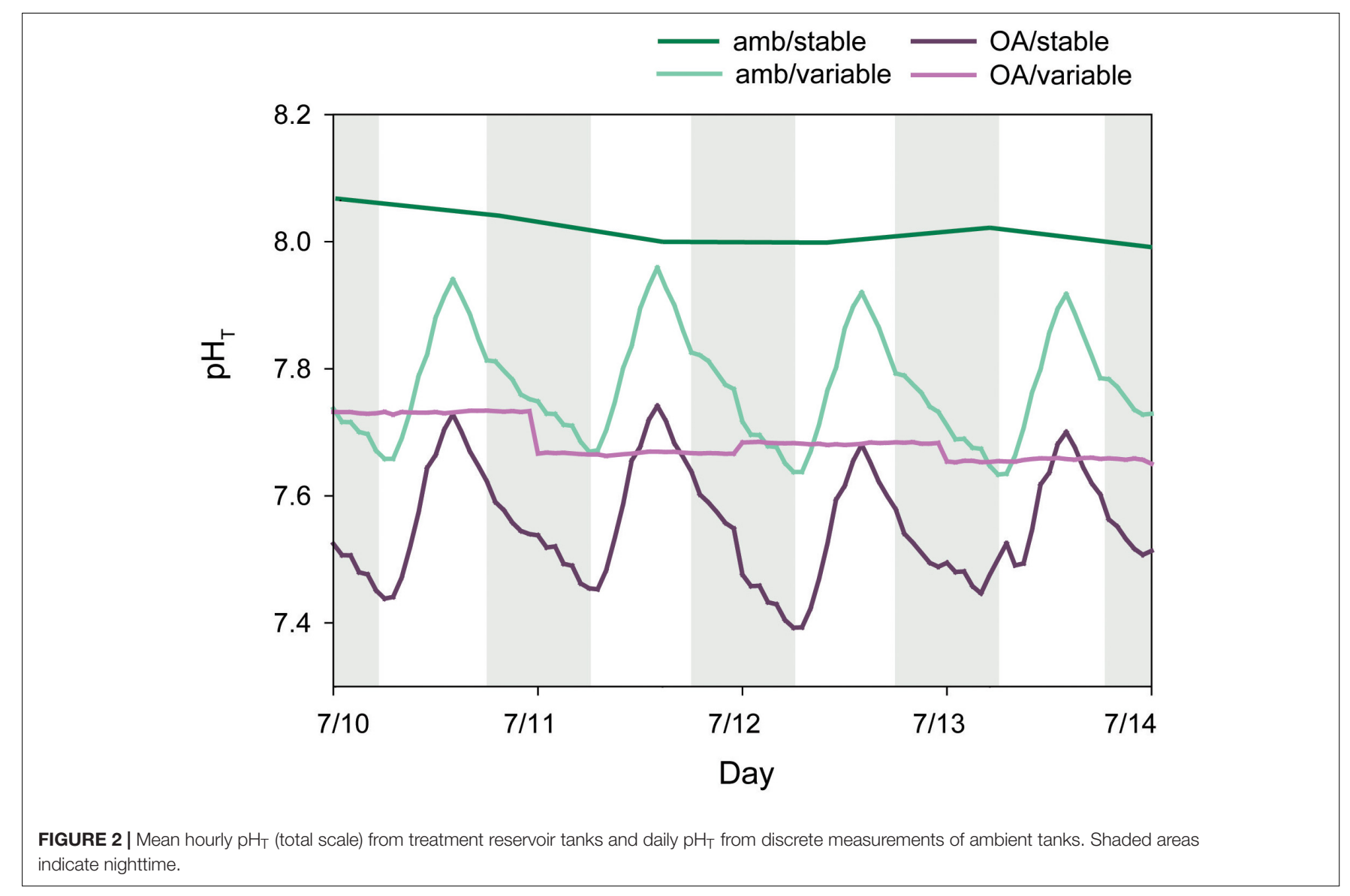

Water samples were collected from reservoir tanks, a subset of treatment tanks, and the ambient seawater line each week for total alkalinity $\left(\mathrm{A}_{\mathrm{T}}\right)$ determinations. Samples were either titrated within 12-h of collection or poisoned with $200 \mu \mathrm{L}$ of a saturated mercuric chloride solution for later processing. $\mathrm{A}_{\mathrm{T}}$ was determined with modified open-cell potentiometric titrations at room temperature using an automated titrator (Mettler Toledo DL15) fit with a glass $\mathrm{pH}$ electrode (Mettler Toledo DG115-SC). The $\mathrm{pH}$ probe was calibrated with NBS buffers $(4,7$, and 10$)$ at the start of each day of titrations. Titrations followed standard operating protocol (SOP) 3b (Dickson et al., 2007), and used certified titrant (A. Dickson). Accuracy of $\mathrm{A}_{\mathrm{T}}$ determinations was evaluated by titrating certified reference material (Batch 158, Reference Material for Oceanic $\mathrm{CO}_{2}$ measurements, A. Dickson) at the start of titrations, after every 10 titrations, and again at the end of each day of titrations. $A_{T}$ determinations were accurate to $0.86 \%$ of reference values $(n=25)$. The full carbonate system in seawater was calculated from measured $\mathrm{pH}_{\mathrm{T}}, \mathrm{A}_{\mathrm{T}}$, temperature, and salinity with the R package seacarb (Lavigne et al., 2014).

All treatment parameters, including the average daily minimum and maximum $\mathrm{pH}_{\mathrm{T}}$ from reservoir tanks, are presented in Table 1.

\section{Response Variables}

Lithophyllum congestum fragments were buoyant weighed at the start of the experiment, after 8 weeks, and again after 16 weeks to determine net calcification rates (Davies, 1989). Buoyant weights were converted to dry weights based on the density of calcite. Calcification rates were normalized to initial fragment weight, and are expressed as $\mathrm{mg} \mathrm{CaCO}_{3} \mathrm{mg}^{-1} \mathrm{day}^{-1}$. Total net calcification rates were calculated over the full duration of the experiment ( $0-16$ weeks). Calcification rates were also calculated for the first (0-8 weeks) and second (8-16 weeks) halves of the experiment, to assess the potential for acclimatization to treatment conditions.

Instantaneous photophysiology was assessed with a blue light pulse-amplitude modulated fluorometer (Junior-PAM, Walz) at the start and end of the experiment. Maximum quantum yield $\left(\mathrm{F}_{\mathrm{v}} / \mathrm{F}_{\mathrm{m}}\right)$ measurements were taken on fragments that were dark adapted for at least $1 \mathrm{~h}$ following sunset. One measurement was taken from three different tips of each $L$. congestum fragment ( $n=3$ measurements per fragment), with the probe held $\sim 1 \mathrm{~mm}$ away from the tissue surface at a constant angle. Settings were optimized to yield initial fluorescence measurements of $\mathrm{F}_{0}=300$ 500 units. Measuring light intensity was minimized to reduce actinic effects and gain was minimized to avoid amplifying noise (Fitt et al., 2001). The same settings were used for all measurements (saturation intensity $=12$, saturation pulse width $=0.8$, measuring light intensity $=8$, frequency $=2$, and gain $=1$ ). Maximum quantum yield provides a useful proxy for photosynthetic efficiency because it is proportional to the rate of electron transport, and it provides a non-invasive and 
TABLE 1 | Mean ( \pm SE) physical conditions of treatments calculated from daily discrete measurements and weekly water samples.

\begin{tabular}{|c|c|c|c|c|c|c|c|c|c|c|}
\hline Treatment & $\mathrm{pH}_{\mathrm{T}}$ & Diel $\min \mathrm{pH}_{\mathrm{T}}$ & Diel $\max \mathrm{pH}_{\mathrm{T}}$ & Diel $\Delta \mathrm{pH}_{\mathrm{T}}$ & Temp & Salinity & $\mathbf{A}_{T}$ & $p \mathrm{CO}_{2}$ & $\mathrm{C}_{\mathrm{T}}$ & $\Omega_{C}$ \\
\hline amb/stable & $8.04(0.004)$ & $7.92(0.007)$ & $8.05(0.006)$ & 0.13 & $29.2(0.08)$ & $32.2(0.16)$ & $2134(11)$ & $386(4)$ & 1841 (3) & $5.21(0.06)$ \\
\hline amb/variable & $7.76(0.005)$ & 7.67 (0.005) & $7.94(0.004)$ & 0.27 & $28.9(0.07)$ & $32.2(0.16)$ & $2126(13)$ & $815(10)$ & 1967 (5) & $3.02(0.03)$ \\
\hline OA/stable & $7.70(0.004)$ & $7.68(0.004)$ & $7.72(0.005)$ & 0.04 & $29.0(0.07)$ & $32.2(0.16)$ & $2132(15)$ & $918(6)$ & $1990(6)$ & $2.68(0.03)$ \\
\hline OA/variable & $7.58 \pm 0.006$ & 7.45 (0.009) & $7.75(0.010)$ & 0.30 & $28.8(0.07)$ & $32.2(0.16)$ & $2128(14)$ & $1241(12)$ & $2022(5)$ & $2.09(0.03)$ \\
\hline
\end{tabular}

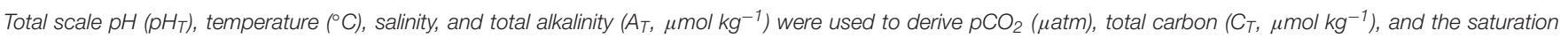

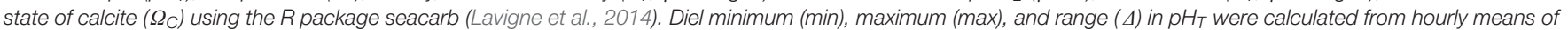
reservoir tanks and discrete measurements of ambient seawater.

instantaneous estimate of the performance of the photosynthetic machinery in algae (Kolber and Falkowski, 1993; Hader and Figueroa, 1997).

\section{Statistics}

Experimental parameters are presented as treatment averages, calculated from the daily means of replicate tanks within each treatment. For maximum quantum yield, the three measurements for a given fragment were averaged and the fragment mean was used in subsequent analyses.

All statistical analyses were performed in $\mathrm{R}$ version 3.4.2 with the untransformed data. Each response variable was evaluated with a separate linear mixed-effects models using the package lme4 (Bates et al., 2015). For total calcification rate and photophysiology, the full model included treatment as a fixed factor and tank as a random factor nested within treatment. We chose to keep the random tank factor in all models to account for potential pseudoreplication issues from having multiple fragments within a tank. To evaluate calcification rates over time, the full model also included time period (0-8 or 8-16 weeks) as a fixed factor and individual as a random factor. Models were fit with maximum likelihood and the significance of fixed factors was evaluated with type II ANOVA tables using Satterthwaite's method. Significant differences between treatments were determined with Tukey's post hoc pairwise comparisons using the package emmeans (Lenth, 2018).

\section{RESULTS}

\section{Total Net Calcification Rate}

Total net calcification rates of $L$. congestum over the full duration of the experiment (0-16 weeks) were significantly lower in all $\mathrm{pH}$ treatments relative to the ambient control (amb/stable) $\left(F_{3,24}=15.62, p<0.001\right)$. Total calcification rates were 27 and $29 \%$ lower in the amb/variable and $\mathrm{OA} /$ stable treatment than in the ambient controls. Corallines in the OA/variable treatment demonstrated the most severe calcification response, with a $60 \%$ reduction in calcification rates relative to ambient controls (Figure 3A).

\section{Net Calcification Rate Over Time}

There was a significant interactive effect of treatment and time $\left(F_{3,67}=5.06, p=0.003\right)$ on $L$. congestum calcification when rates were partitioned into the first and second halves of the experiment. Calcification rates remained unchanged between the first and second half of the experiment in the OA/stable treatment $(p=0.481)$ and amb/stable control $(p=0.307)$, but magnified over time in both of the variable treatments with rates decreasing from the first to second half of the experiment $(p<0.001$ for both amb/variable and OA/variable treatments) (Figure 3B). After 0-8 weeks of exposure, CCA calcification rates in the $\mathrm{amb} /$ variable treatment were $16 \%$ lower than ambient controls, and from 8 to 16 weeks calcification rates were $47 \%$ lower than the respective ambient controls. In the $\mathrm{OA} /$ variable treatment, the reduction in calcification rates relative to ambient controls was

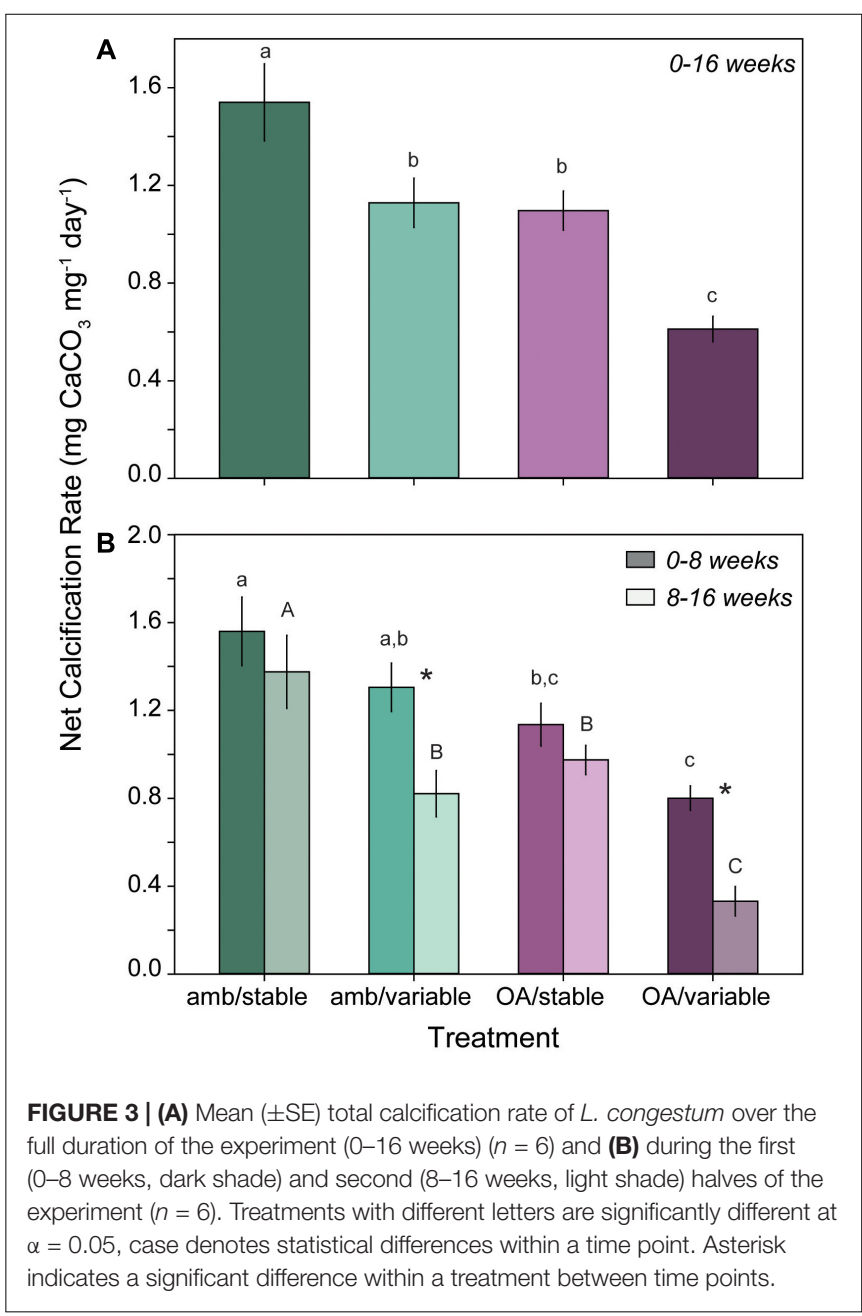




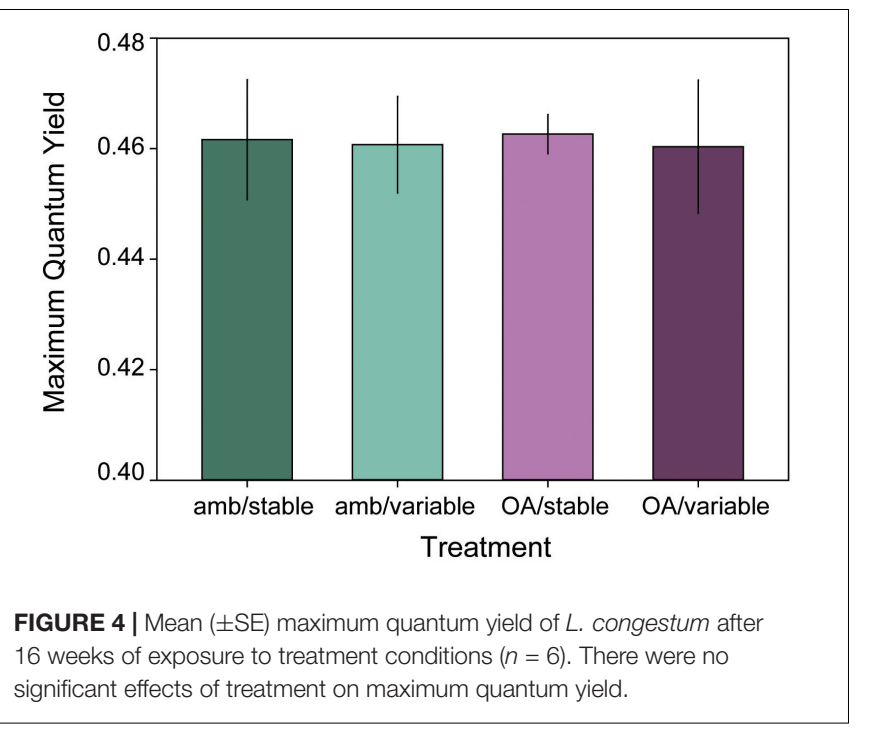

49 and $79 \%$ from 0 to 8 and 8-16 weeks, respectively. Conversely, calcification rates in the $\mathrm{OA} /$ stable treatment ranged from 27 to $37 \%$ lower than controls, but did not differ significantly between time points (Figure 3B).

\section{Maximum Quantum Yield}

Initial maximum quantum yield was the same for $L$. congestum fragments randomly assigned to each treatment $\left(F_{3,24}=0.50\right.$, $p=0.683)$. Mean $( \pm \mathrm{SE})$ initial yields by treatment were $0.48 \pm 0.01$ (amb/stable, amb/var), $0.46 \pm 0.02$ (stable/OA), and $0.47 \pm 0.004(\mathrm{OA} / \mathrm{var})$. There were no differences among treatments in maximum quantum yield at the end of the 16-week experiment (Figure 4) $\left(F_{3,24}=0.01, p=0.998\right)$, and no significant change in yield over time $\left(F_{1,43}=2.58, p=0.113\right)$.

\section{DISCUSSION}

Here, we demonstrate that exposure to diel $\mathrm{pH}$ cycling influenced the response of a common reef-building CCA to OA, and that $\mathrm{pH}$ variability and $\mathrm{OA}$ synergistically decreased calcification. Instead of increasing tolerances to low $\mathrm{pH}$, as predicted by environmental variability-stress acclimatization theory (Boyd et al., 2016), variability exacerbated the negative effects of $\mathrm{OA}$ on coralline net calcification. Notably, the magnitude of treatment responses changed over time, with both variable treatments having stronger negative effects with longer duration of exposure. In contrast to the calcification response, photophysiology was unaffected by $\mathrm{pH}$ treatment, which indicates that the effects of $\mathrm{pH}$ treatment on calcification were independent of photosynthetic processes. Our results show that $\mathrm{pH}$ variability does not inherently increase the tolerance of tropical CCA to OA, and suggests that both $\mathrm{pH}$ variability and exposure time could be important factors underlying differential responses to OA. Moreover, our findings indicate that $\mathrm{OA}$ combined with diel $\mathrm{pH}$ cycling can have synergistic and extreme negative effects.
When we normalized the net calcification response of L. congestum over the full duration of the experiment (0-16 weeks), the amb/variable and OA/stable treatment decreased calcification rates by the same magnitude relative to ambient controls (amb/stable). This is notable because corallines in the amb/variable treatment were exposed to low $\mathrm{pH}$ conditions for roughly half the amount of time as the corallines in the $\mathrm{OA} /$ stable treatment. Further, $\mathrm{pH}$ variability combined with $\mathrm{OA}$ (i.e., OA/variable) had the most extreme effect on calcification, decreasing rates by $60 \%$ relative to ambient controls. These results are intriguing because they suggest that, overall, ambient $\mathrm{pH}$ variability (amb/variable) incurred the same cost to calcification as the OA/stable treatment. Moreover, simultaneous exposure to lower $\mathrm{pH}$ and variability exacerbated the negative effects of OA.

Exposure to variability can influence physiological responses to environmental stress, independent of environmental history. A complete discussion of the role of environmental history in the response of tropical coralline algae to OA, and potential mechanisms underpinning acclimatization, are reviewed in Rivest et al., 2017. Here, we considered only the effect of continued exposure to $\mathrm{pH}$ variability on the tropical CCA L. congestum, with no change in regime (i.e., treatment) over the course of the experiment.

Diel $\mathrm{pH}$ variability could increase CCA tolerances to OA by providing periods of reprieve from low $\mathrm{pH}$ (Rivest et al., 2017). For example, higher $\mathrm{pH}$ during the day could provide a favorable timeframe for active calcification, compensating for decreased calcification during periods of lower $\mathrm{pH}$ at night (Comeau et al., 2013a; Cornwall et al., 2018). Alternatively, low pH at night could drive dissolution and counteract any benefits of high $\mathrm{pH}$ during the day (Cornwall et al., 2013). Furthermore, the rate of change in $\mathrm{pH}$ can elicit stronger negative responses than exposure to stable low $\mathrm{pH}$. For example, calcification and skeletal structure of the temperate CCA Lithothamnion glaciale was more sensitive to rapid decreases in $\mathrm{pH}$, simulating $\mathrm{pH}$ changes associated with upwelling or carbon capture and release, than chronic exposure to stable, low pH (Kamenos et al., 2013). This suggests that daily exposure to rapid $\mathrm{pH}$ changes could have long-term negative consequences for calcification in tropical CCA. Thus, the switch between these alternative scenarios could depend on both the magnitude and rate of change over the course of the diel cycle. Our results support the latter, indicating that cyclic exposure to low $\mathrm{pH}$ has net detrimental effects on CCA calcification. This could be due to a non-linear relationship between $\mathrm{pH}$ and calcification, or some lag in resumption of calcification after $\mathrm{pH}$ returns to favorable levels.

Our total calcification responses concur with Cornwall et al. (2013), which found that ambient variable $\mathrm{pH}$ decreased relative growth of the temperate articulated coralline Arthrocardia corymbosa by the same amount as stable OA. Coralline recruits from the same study responded, similarly (Roleda et al., 2015). As with our results, they found that fluctuating $\mathrm{pH}$ combined with OA had the most extreme effects and synergistically decreased growth of adults and recruits (Cornwall et al., 2013; Roleda et al., 2015). Johnson et al. (2014a) also found similar results for the tropical CCA Porolithon onkodes, where calcification rates 
were lower in variable $\mathrm{pH}$ conditions than ambient controls. Our results conflict with those of Cornwall et al. (2018), which found the tropical CCA $H$. reinboldii was unaffected by exposure to either $\mathrm{pH}$ variability, $\mathrm{OA}$, or the combination of both. Our results contribute to a growing body of studies that demonstrate $\mathrm{pH}$ variability generally decreases calcification in tropical CCA, and suggests that the results with $H$. reinboldii in the Cornwall et al. (2018) study may be an exception worthy of further examination.

Comparing overall net calcification responses across experiments is difficult due to species-specific physiology and differences in duration of experiments ranging from 14 days (Johnson et al., 2014a) and 40 days (Cornwall et al., 2013) to 100-112 days (Cornwall et al., 2018, present study). Given the similarities in design (e.g., treatments and duration) between our study and Cornwall et al. (2018), we might expect to see similar responses. However, Cornwall et al. (2018) found no response to $\mathrm{pH}$ variability or $\mathrm{OA}$, and hypothesized that the lack of response in $H$. reinboldii was a result of physiological control over calcification. They further concluded that physiological control may be species-specific. While intracellular control over calcification has been recognized as a potential underlying mechanism for species-specific tolerances to $\mathrm{OA}$ in corals (Comeau et al., 2013b), it has only recently been identified as a potential mechanism for CCA (Cornwall et al., 2017). Thus, differences between these studies may be related to taxa-specific calcification mechanisms. While L. congestum and $H$. reinboldii are morphologically similar in their production of blunt branches, they may be fundamentally different with respect to calcification physiology. Future work should take a comparative approach to elucidating mechanisms of calcification across coralline species, as we know little about interspecific variation in calcification physiology.

Time is a critical component for organismal acclimatization, especially given that compensatory changes in cellular machinery take time to manifest following the onset of stressful conditions (Comeau et al., 2018). However, the negative effects of prolonged exposure to stressful conditions can also compound over time. For example, repeated exposure to thermal stress can increase bleaching susceptibility in corals (Schoepf et al., 2015). When we partitioned net calcification into the first and second halves of the experiment, calcification responses to the variable treatments, but not stable OA, changed with longer duration of exposure. Instead of facilitating acclimatization to $\mathrm{pH}$ conditions, $\mathrm{pH}$ variability increased the sensitivity of L. congestum over time. For example, the magnitude of decrease in calcification in the amb/variable and OA/variable treatments relative to ambient controls doubled between $0-8$ weeks and 8-16 weeks. Conversely, the magnitude of the OA/stable treatment effect stayed the same between time points. These are the first results to explore a temporal component to tropical CCA responses to $\mathrm{pH}$ regimes in the lab. The temperate CCA L. glaciale showed some temporal variation in response to simulated $\mathrm{OA}$ and warming throughout a 1-year experiment, but overall showed no clear trend toward acclimatization or compounding negative effects over time (Martin and Gattuso, 2009).
Though discerning the mechanisms underlying the increased sensitivity of $L$. congestum to $\mathrm{pH}$ variability over time is beyond the scope of this study, we propose a few potential mechanisms that could explain this response. First, dissolution under low $\mathrm{pH}$ at night may have counteracted any benefits to calcification of higher $\mathrm{pH}$ during the day (Rivest et al., 2017). Part of this may be that these CCA may already be living below their optimal $\mathrm{pH}$ range and additional fluctuations push them beyond their tolerance threshold. Second, constant exposure to low $\mathrm{pH}$ (as in the OA/stable treatment) may have initiated the up- or downregulation of cellular machinery necessary for regulating internal pH (Comeau et al., 2018). Furthermore, exposure to fluctuating conditions may have been insufficient to trigger initiation of the physiological mechanisms underlying phenotypic plasticity or may have outright inhibited it. Importantly, alterations in gene expression take time to manifest, and fluctuating $\mathrm{pH}$ regimes may have inhibited the changes in expression that underly acclimatization. Third, the species used in this study, L. congestum, may not have the same capacity for internal $\mathrm{pH}$ control, or other mechanisms that facilitate calcification under fluctuating $\mathrm{pH}$, that was recently documented in other corallines (Cornwall et al., 2017). Future experiments should explore if other tropical CCA species demonstrate similar sensitivities to variability and OA over time and identify the underlying mechanisms.

An important caveat to the present study is that the experiment took place over the course of 16 weeks (120 days), whereas the changes in $\mathrm{pH}$ associated with $\mathrm{OA}$ are occurring over decades-to-centuries. Thus, scaling the results of this relatively short-term laboratory experiment to the long-term effects of OA is limited by our inability to fully simulate the rate of $\mathrm{pH}$ change occurring with OA. In nature, the response of tropical CCA to OA will be shaped by a multitude of interacting biotic and abiotic factors accumulating over time. Given the significant role of $\mathrm{pH}$ variability in shaping CCA responses to mean reductions in $\mathrm{pH}$ documented here, natural variation will likely mediate in situ responses to the longer-term reductions in $\mathrm{pH}$ due to OA.

Though L. congestum showed a distinct calcification response to $\mathrm{pH}$, photophysiology (i.e., maximum quantum yield) was unaffected. The yield values we measured are relatively low, and this may be due to where on the algal thallus we took the readings. Quantum yield from branching CCA morphologies, like $L$. congestum, can vary depending on if the measurements is taken from a branch tip or near the base (Burdett et al., 2012). Our measurements were taken from branch tips, where tissues were more lightly pigmented. Indeed, our average yield is similar to those measured from the upward facing branch tips of a CCA in the Red Sea (L. kotschyanum) (Burdett et al., 2014). Quantum yield was measured the same across all treatments, and though yield values were lower than expected, we would still expect to detect treatment effects if they were present.

Calcification and photosynthesis are tightly coupled, where photosynthesis provides the energy for calcification and can increase internal pH at the site of calcification (Borowitzka, 1981). Understanding how each process is affected by OA provides insight into potential physiological mechanisms underlying the response of calcification to changes in $\mathrm{pH}$. The lack of response 
in maximum quantum yield across our experimental treatments suggests that the response of calcification to variation in $\mathrm{pH}$ was independent of any changes to photosynthesis. However, these results should be interpreted cautiously, because quantum yield is only a proxy for photosynthesis and it may not be as accurate for algae with abundant accessory pigments. CCA are red algae that possess phycobilin pigments (Kursar and Alberte, 1983). Any change in phycobilin pigment content or contribution to higher photosynthetic rates may not have been detected. Other studies have found mixed effects of OA on algal photophysiology (Koch et al., 2013). For example, photosynthetic rates and pigment content in tropical CCA are sometimes enhanced by lower $\mathrm{pH}$ (Johnson and Carpenter, 2018), but in other cases they are negatively impacted (Anthony et al., 2008) or not affected (Johnson et al., 2014b). More accurate techniques, such as oxygen evolution incubations, should be used to accurately assess the effects of OA on photosynthesis in CCA (Hurd et al., 2009).

\section{CONCLUSION}

Here, we provide evidence that negative effects of $\mathrm{pH}$ variability on calcification of a tropical CCA intensified over time and increased sensitivity to OA. This is among the first studies to quantify a temporal component to CCA response to $\mathrm{pH}$ variability and $\mathrm{OA}$, and sheds light on the dynamic nature of organismal responses to environmental stress over time. Moreover, our findings illustrate the potential synergistic effects of $\mathrm{OA}$ and diel $\mathrm{pH}$ variability, which has important implications for nearshore ecosystems where environmental conditions fluctuate over a diel cycle. Notably, our findings do not support the theory that variability inherently increases calcifier tolerances to OA stress. These results imply that environmentally variable nearshore habitats may not provide a refuge from environmental stress associated with global change, but may in fact be the most vulnerable ecosystems due to heightened sensitivity of calcifiers to predicted OA.

\section{REFERENCES}

Adey, W. H. (1978). Algal rides of the Caribbean and West-Indies. Phycologia 17, 361-367. doi: 10.2216/i0031-8884-17-4-361.1

Adey, W. H. (1998). Coral reefs: algal structured and mediated ecosystems in shallow, turbulent, alkaline waters. J. Phycol. 34, 393-406. doi: 10.1046/j.15298817.1998.340393.x

Anthony, K. R. N., Kleypas, J. A., and Gattuso, J. P. (2011). Coral reefs modify their seawater carbon chemistry - implications for impacts of ocean acidification. Glob. Chang. Biol. 17, 3655-3666. doi: 10.1111/j.1365-2486.2011. 02510.x

Anthony, K. R. N., Kline, D. I., Diaz-Pulido, G., Dove, S., and Hoegh-Guldberg, O. (2008). Ocean acidification causes bleaching and productivity loss in coral reef builders. Proc. Natl. Acad. Sci. U.S.A. 105, 17442-17446. doi: 10.1073/pnas. 0804478105

Bates, D., Maechler, M., Bolker, B., and Walker, S. (2015). Fitting linear mixedeffects models using lme4. J. Stat. Softw. 67, 1-48. doi: 10.18637/jss.v067.i01

Borowitzka, M. A. (1981). Photosynthesis and calcification in the articulated coralline red algae Amphiroa anceps and Amphiroa foliacea. Mar. Biol. 62, 17-23. doi: 10.1007/BF00396947

\section{DATA AVAILABILITY}

The datasets generated for this study are available on request to the corresponding author.

\section{AUTHOR CONTRIBUTIONS}

MJ conceived and designed the experiments and analyzed the data. MJ, LRB, NV, and SO implemented the experiments. MJ and AA interpreted the data, wrote the manuscript, and secured the financial support. All authors edited the manuscript and approved the final submission.

\section{FUNDING}

This work was supported by Smithsonian Institution Marine Global Earth Observatory (MarineGEO) and Smithsonian Tropical Research Institute (STRI) postdoctoral fellowships to $\mathrm{MJ}$, and by STRI funds to AA. NV received internship support from STRI Academic Programs and the University of Chicago International Experience Grant. SO received internship support from the Miller Worly Center for the Environment at Mount Holyoke College. Research permits were provided by the Autoridad Nacional del Ambiente de Panamá.

\section{ACKNOWLEDGMENTS}

We thank Rachel Collin for facilities support at the Bocas del Toro Research Station, Plinio Gondola, and the research station staff for logistical support. We are grateful to the lab and field assistance from Nicte-Ha Muñoz, Manuel Rodriguez Bravo, and William Wied, and for critical feedback from Mike Fox. We also thank Sophie McCoy and Heidi Burdett for their constructive feedback. This is contribution 36 from the Smithsonian's MarineGEO network.

Bosence, D. W. J. (1985). The morhology and ecology of a mound-building coralline alga (Neogoniolithon strictum) from the Florida Keys. Palaeontology 28, 189-206.

Boyd, P. W., Cornwall, C. E., Davison, A., Doney, S. C., Fourquez, M., Hurd, C. L., et al. (2016). Biological responses to environmental heterogeneity under future ocean conditions. Glob. Chang. Biol. 22, 2633-2650. doi: 10.1111/gcb.13287

Burdett, H. L., Hennige, S. J., Francis, F. T. Y., and Kamenos, N. A. (2012). The photosynthetic characteristics of red coralline algae, determined using pulse amplitude modulation (PAM) fluorometry. Botanica Marina 55, 499-509. doi: 10.1515/bot-2012-0135

Burdett, H. L., Keddie, V., MacArthur, N., McDowall, L., McLeish, J., Spielvogel, E., et al. (2014). Dynamic photoinhibition exhibited by red coralline algae in the red sea. BMC Plant Biol. 14:139. doi: 10.1186/1471-2229-14-139

Comeau, S., Carpenter, R. C., and Edmunds, P. J. (2013a). Coral reef calcifiers buffer their response to ocean acidification using both bicarbonate and carbonate. Proc. R. Soc. B Biol. Sci. 280:20122374. doi: 10.1098/rspb.2012.2374

Comeau, S., Edmunds, P. J., Spindel, N. B., and Carpenter, R. C. (2013b). The responses of eight coral reef calcifiers to increasing partial pressure of $\mathrm{CO} 2$ do not exhibit a tipping point. Limnol. Oceanogr. 58, 388-398. doi: 10.4319/lo.2013. 58.1 .0388 
Comeau, S., Cornwall, C. E., DeCarlo, T. M., Krieger, E., and McCulloch, M. T. (2018). Similar controls on calcification under ocean acidification across unrelated coral reef taxa. Glob. Chang. Biol. 24, 4857-4868. doi: 10.1111/gcb.14379

Comeau, S., Lantz, C. A., Edmunds, P. J., and Carpenter, R. C. (2016). Framework of barrier reefs threatened by ocean acidification. Glob. Chang. Biol. 22, 1225-1234. doi: 10.1111/gcb.13023

Cornwall, C. E., Comeau, S., DeCarlo, T. M., Moore, B., D’Alexis, Q., and McCulloch, M. T. (2018). Resistance of corals and coralline algae to ocean acidification: physiological control of calcification under natural $\mathrm{pH}$ variability. Proc. R. Soc. B Biol. Sci. 285:20181168. doi: 10.1098/rspb.2018.1168

Cornwall, C. E., Comeau, S., and McCulloch, M. T. (2017). Coralline algae elevate $\mathrm{pH}$ at the site of calcification under ocean acidification. Glob. Chang. Biol. 23, 4245-4256. doi: 10.1111/gcb.13673

Cornwall, C. E., Hepburn, C. D., McGraw, C. M., Currie, K. I., Pilditch, C. A., Hunter, K. A., et al. (2013). Diurnal fluctuations in seawater $\mathrm{pH}$ influence the response of a calcifying macroalga to ocean acidification. Proc. Biol. Sci. 280:20132201. doi: 10.1098/rspb.2013.2201

Davies, P. S. (1989). Short-term growth measurements of corals using an accurate buoyant weighing technique. Mar. Biol. 101, 389-395. doi: 10.1007/BF00428135

Dickson, A. G., Sabine, C. L., and Christian, J. R. (2007). Guide to Best Practices for Ocean CO2 Measurements. Sidney: North Pacific Marine Science Organization.

Duarte, C. M., Hendriks, I. E., Moore, T. S., Olsen, Y. S., Steckbauer, A., Ramajo, L., et al. (2013). Is ocean acidification an open-ocean syndrome? Understanding anthropogenic impacts on seawater pH. Estuaries Coasts 36, 221-236. doi: 10.1007/s12237-013-9594-3

Edmunds, P. J., Comeau, S., Lantz, C., Andersson, A., Briggs, C., Cohen, A., et al. (2016). Integrating the effects of ocean acidification across functional Scales on tropical coral reefs. Bioscience 66, 350-362. doi: 10.1093/biosci/biw023

Eyre, B. D., Andersson, A. J., and Cyronak, T. (2014). Benthic coral reef calcium carbonate dissolution in an acidifying ocean. Nat. Clim. Change 4, 969-976. doi: $10.1038 /$ nclimate2380

Fitt, W. K., Brown, B. E., Warner, M. E., and Dunne, R. P. (2001). Coral bleaching: interpretation of thermal tolerance limits and thermal thresholds in tropical corals. Coral Reefs 20, 51-65. doi: 10.1007/s003380100146

Georgiou, L., Falter, J., Trotter, J., Kline, D. I., Holcomb, M., Dove, S. G., et al. (2015). pH homeostasis during coral calcification in a free ocean CO2 enrichment (FOCE) experiment, Heron Island reef flat, Great Barrier Reef. Proc. Natl. Acad. Sci. U.S.A. 112, 13219-13224. doi: 10.1073/pnas.1505586112

Guadayol, Ò, Silbiger, N. J., Donahue, M. J., and Thomas, F. I. (2014). Patterns in temporal variability of temperature, oxygen and $\mathrm{pH}$ along an environmental gradient in a coral reef. PLoS One 9:e85213. doi: 10.1371/journal.pone.0085213

Hader, D. P., and Figueroa, F. L. (1997). Photoecophysiology of marine macroalgae. Photochem. Photobiol. 66, 1-14. doi: 10.1016/j.marenvres.2014.07.012

Hartin, C., Bond-Lamberty, B., Patel, P., and Mundra, A. (2016). Ocean acidification over the next three centuries using a simple global climate carboncycle model: projections and sensitivities. Biogeosciences 13, 4329-4342. doi: 10.5194/bg-13-4329-2016

Hoegh-Guldberg, O., Mumby, P. J., Hooten, A. J., Steneck, R. S., Greenfield, P., Gomez, E., et al. (2007). Coral reefs under rapid climate change and ocean acidification. Science 318, 1737-1742. doi: 10.1126/science.1152509

Hofmann, G. E., Smith, J. E., Johnson, K. S., Send, U., Levin, L. A., Micheli, F., et al. (2011). High-frequency dynamics of ocean $\mathrm{pH}$ : a multi-ecosystem comparison. PLoS One 6:e28983. doi: 10.1371/journal.pone.0028983

Hurd, C. L., Hepburn, C. D., Currie, K. I., Raven, J. A., and Hunter, K. A. (2009). Testing the effects of ocean acidification on algal metabolism: considerations for experimental designs. J. Phycol. 45, 1236-1251. doi: 10.1111/j.1529-8817.2009. 00768.x

Johnson, M. D., and Carpenter, R. C. (2018). Nitrogen enrichment offsets direct negative effects of ocean acidification on a reef-building crustose coralline alga. Biol. Lett. 14:20180371. doi: 10.1098/rsbl.2018.0371

Johnson, M. D., Moriarty, V. W., and Carpenter, R. C. (2014a). Acclimatization of the crustose coralline alga Porolithon onkodes to variable pCO2. PLoS One 9:e87678. doi: 10.1371/journal.pone.0087678

Johnson, M. D., Price, N. N., and Smith, J. E. (2014b). Contrasting effects of ocean acidification on tropical fleshy and calcareous algae. PeerJ 2:E411. doi: $10.7717 /$ peerj.411

Kamenos, N. A., Burdett, H. L., Aloisio, E., Findlay, H. S., Martin, S., Longbone, C., et al. (2013). Coralline algal structure is more sensitive to rate, rather than the magnitude, of ocean acidification. Glob. Chang. Biol. 19, 3621-3628. doi: $10.1111 /$ gcb. 12351

Kleypas, J. A., Anthony, K. R. N., and Gattuso, J. P. (2011). Coral reefs modify their seawater carbon chemistry - case study from a barrier reef (Moorea, French Polynesia). Glob. Chang. Biol. 17, 3667-3678. doi: 10.1111/j.1365-2486.2011. 02530.x

Kline, D. I., Teneva, L., Schneider, K., Miard, T., Chai, A., Marker, M., et al. (2012). A short term in situ CO2 enrichment experiment on Heron Island (GBR). Sci. Rep. 2:413. doi: 10.1038/srep00413

Koch, M., Bowes, G., Ross, C., and Zhang, X.-H. (2013). Climate change and ocean acidification effects on seagrasses and marine macroalgae. Glob. Chang. Biol. 19, 103-132. doi: 10.1111/j.1365-2486.2012.02791.x

Kolber, Z., and Falkowski, P. G. (1993). Use of active fluorescence to estimate phytoplankton photosynthesis in situ. Limnol. Oceanogr. 38, 1646-1665. doi: 10.4319/lo.1993.38.8.1646

Kroeker, K. J., Kordas, R. L., Crim, R. N., and Singh, G. G. (2010). Meta-analysis reveals negative yet variable effects of ocean acidification on marine organisms. Ecol. Lett. 13, 1419-1434. doi: 10.1111/j.1461-0248.2010.01518.x

Kroeker, K. J., Micheli, F., and Gambi, M. C. (2013). Ocean acidification causes ecosystem shifts via altered competitive interactions. Nat. Clim. Change 3:156. doi: $10.1038 /$ nclimate 1680

Kursar, T. A., and Alberte, R. S. (1983). Photosynthetic unit organization in a red alga- relationships between light-harvesting pigmetns and reaction centers. Plant Physiol. 72, 409-414. doi: 10.1104/pp.72.2.409

Lavigne, H., Epitalon, J.-M., and Gattuso, J.-P. (2014). seacarb: Seawater Carbonate Chemistry with R. R Package Version 3.0. Available at: https://cran.r-project.org/ package $=$ seacarb.

Lenth, R. (2018). Emmeans: Estimated Marginal Means, Aka Least-Squares Means. $R$ Package Version 1.2. Available at: https://mran.microsoft.com/snapshot/ 2018-03-30/web/packages/emmeans/index.html.

Martin, S., and Gattuso, J. P. (2009). Response of Mediterranean coralline algae to ocean acidification and elevated temperature. Glob. Chang. Biol. 15, 2089-2100. doi: $10.1002 /$ ece 3.475

Mayfield, A. B., Chan, P. H., Putnam, H. M., Chen, C. S., and Fan, T. Y. (2012). The effects of a variable temperature regime on the physiology of the reef-building coral Seriatopora hystrix: results from a laboratory-based reciprocal transplant. J. Exp. Biol. 215, 4183-4195. doi: 10.1242/jeb.071688

McCoy, S. J., and Kamenos, N. A. (2015). Coralline algae (Rhodophyta) in a changing world: integrating ecological, physiological, and geochemical responses to global change. J. Phycol. 51, 6-24. doi: 10.1111/jpy.12262

Noisette, F., Egilsdottir, H., Davoult, D., and Martin, S. (2013). Physiological responses of three temperate coralline algae from contrasting habitats to nearfuture ocean acidification. J. Exp. Mar. Biol. Ecol. 448, 179-187. doi: 10.1016/j. jembe.2013.07.006

Padilla-Gamiño, J. L., Gaitán-Espitia, J. D., Kelly, M. W., and Hofmann, G. E. (2016). Physiological plasticity and local adaptation to elevated pCO2 in calcareous algae: an ontogenetic and geographic approach. Evol. Appl. 9, 1043-1053. doi: 10.1111/eva.12411

Palumbi, S. R., Barshis, D. J., Traylor-Knowles, N., and Bay, R. A. (2014). Mechanisms of reef coral resistance to future climate change. Science 344 895-898. doi: 10.1126/science. 1251336

Price, N. N., Martz, T. R., Brainard, R. E., and Smith, J. E. (2012). Diel variability in seawater $\mathrm{pH}$ relates to calcification and benthic community structure on coral reefs. PLoS One 7:e43843. doi: 10.1371/journal.pone.0043843

Rivest, E. B., Comeau, S., and Cornwall, C. E. (2017). The role of natural variability in shaping the response of coral reef organisms to climate change. Curr. Clim. Chang. Rep. 3, 271-281. doi: 10.1007/s40641-017-0082-x

Roleda, M. Y., Cornwall, C. E., Feng, Y., McGraw, C. M., Smith, A. M., and Hurd, C. L. (2015). Effect of ocean acidification and $\mathrm{pH}$ fluctuations on the growth and development of coralline algal recruits, and an associated benthic algal assemblage. PLoS One, 10:e0140394. doi: 10.1371/journal.pone.014 0394

Schoepf, V., Stat, M., Falter, J. L., and McCulloch, M. T. (2015). Limits to the thermal tolerance of corals adapted to a highly fluctuating, naturally extreme temperature environment. Sci. Rep. 5:17639. doi: 10.1038/srep 17639

Smith, J. E., Brainard, R., Carter, A., Grillo, S., Edwards, C., Harris, J., et al. (2016). Re-evaluating the health of coral reef communities: baselines and evidence for 
human impacts across the central Pacific. Proc. R. Soc. B. Biol. Sci. 283:20151985. doi: 10.1098/rspb.2015.1985

Stark, J. S., Peltzer, E. T., Kline, D. I., Queirós, A. M., Cox, T. E., Headley, K., et al. (2019). Free ocean CO2 enrichment (FOCE) experiments: scientific and technical recommendations for future in situ ocean acidification projects. Prog. Oceanogr. 172, 89-107. doi: 10.1016/j.pocean.2019.01.006

Takeshita, Y., Cyronak, T., Martz, T. R., Kindeberg, T., and Andersson, A. J. (2018). Coral reef carbonate chemistry variability at different functional scales. Front. Mar. Sci. 5:175. doi: 10.3389/fmars.2018.00175

van Oppen, M. J., Oliver, J. K., Putnam, H. M., and Gates, R. D. (2015). Building coral reef resilience through assisted evolution. Proc. Natl. Acad. Sci. U.S.A. 112, 2307-2313. doi: 10.1073/pnas.1422301112

Vargas, C. A., Lagos, N. A., Lardies, M. A., Duarte, C., Manriquez, P. H., Aguilera, V. M., et al. (2017). Species-specific responses to ocean acidification should account for local adaptation and adaptive plasticity. Nat. Ecol. Evol. 1:0084. doi: 10.1038/s41559-017-0084
Vargas-Angel, B., Richards, C. L., Vroom, P. S., Price, N. N., Schils, T., Young, C. W., et al. (2015). Baseline assessment of net calcium carbonate accretion rates on US Pacific reefs. PLoS One 10:e0142196. doi: 10.1371/journal.pone. 0142196

Conflict of Interest Statement: The authors declare that the research was conducted in the absence of any commercial or financial relationships that could be construed as a potential conflict of interest.

Copyright (C) 2019 Johnson, Rodriguez Bravo, O'Connor, Varley and Altieri. This is an open-access article distributed under the terms of the Creative Commons Attribution License (CC BY). The use, distribution or reproduction in other forums is permitted, provided the original author(s) and the copyright owner(s) are credited and that the original publication in this journal is cited, in accordance with accepted academic practice. No use, distribution or reproduction is permitted which does not comply with these terms. 